\title{
Estimating surface energy fluxes: a key component for estimating potential evaporation
}

\author{
$\underline{\text { B.F.W. Croke }}$ \\ ${ }^{a}$ Fenner School of Environment and Society, and Mathematical Sciences Institute, Australian National \\ University, Canberra, Australian Capital Territory
}

Email: barry.croke@anu.edu.au

\begin{abstract}
A model has been developed that can predict the solar and infrared downwelling radiation fluxes using ground based measurements of the air temperature, relative humidity and the cloud cover. The algorithm has been validated using several years of ground-based data for 15 sites across the globe (13 sites from the Baseline Surface Radiation Network (BSRN), as well as data for two sites in Crete). These stations cover a wide range of climatic conditions, including those of arctic, desert, sub-tropical, Mediterranean, as well as elevated sites. The RMS residual for the monthly mean short wave (SW) solar flux (approximately 0.2 to $3 \mu \mathrm{m}$ ) is typically $12 \mathrm{Wm}^{-2}$ (mean observed daily SW flux across all stations is 305 $\mathrm{Wm}^{-2}$ ), while the thermal IR flux (roughly 4-50 $\mu \mathrm{m}$ ) derived using the algorithms gives RMS residuals of approximately $8 \mathrm{Wm}^{-2}$ (mean observed daily IR flux across all stations is $180 \mathrm{Wm}^{-2}$ ). Daily observed and modelled fluxes, as well as residuals are shown for 8 of the stations in Figure 1 . As well as the radiation fluxes, the model also estimates the atmospheric water vapour content, which has been tested using available radiosonde data for 8 of the stations. In comparison with the observed mean water vapour content, the values derived by the algorithms have typical values for bias of $0.01 \mathrm{~g} \mathrm{~cm}^{-2}$ and RMS residual of $0.15 \mathrm{~g} \mathrm{~cm}^{-2}$ (mean across all stations is $1.65 \mathrm{~g} \mathrm{~cm}^{-2}$ ), accounting for $80 \%$ of the observed variation. Since the model uses readily available meteorological data, the net radiation flux at the surface can readily be calculated (given the surface albedo), providing an estimate of a dominant term in estimating potential evaporation and evapotranspiration.
\end{abstract}
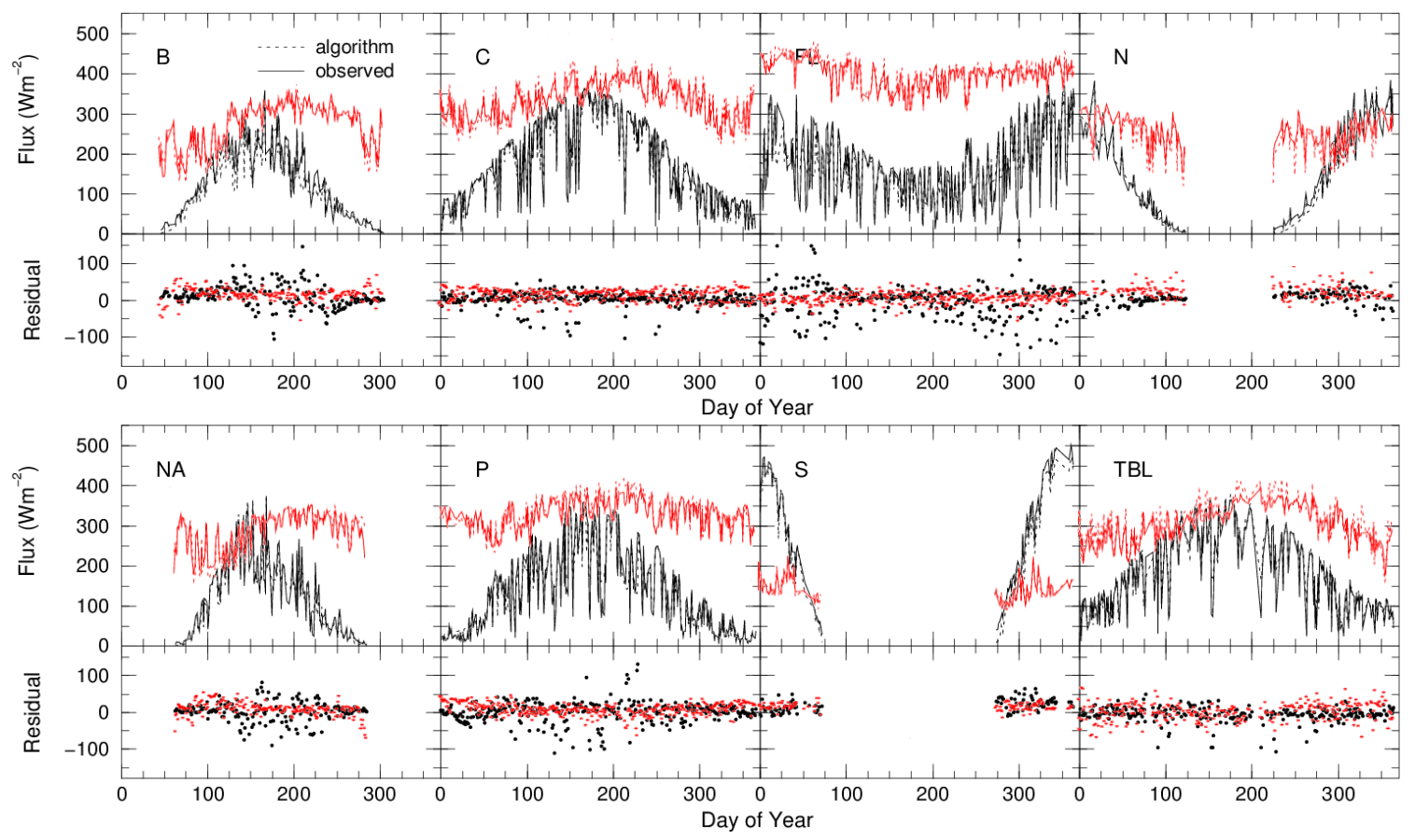

Figure 1. One year of observed and modelled daily solar (black) and infrared (red) radiation for 8 of the study sites spanning a wide range of climates from arctic to tropical.

Keywords: Solar radiation, infra-red radiation, water vapour, potential evaporation 


\section{INTRODUCTION}

Knowledge of the surface radiation budget is important because of its influence on surface temperature, circulation in the atmosphere and oceans, and on the hydrological cycle (Vardavas and Taylor, 2011). While spot measurements of the radiation budget and evapotranspiration can be made, these cannot easily be used to estimate the areal distribution over a catchment. Thus studies of the impact of global change, and the risk of desertification in a catchment require a means of estimating the areal distribution of both the radiation budget and the evapotranspiration. Vardavas and Fountoulakis (1995) presented a simple model for calculating the lake evaporation based on air and water-surface temperature, relative humidity and sunshine hours, and applied the model to four Australian lakes. Their model includes a method of estimating the surface radiation budget for a lake using temperature, relative humidity and sunshine hours, which is developed further in this paper.

Data on the surface radiation budget are limited. Ground-based measurements of the surface solar and longwave radiation fluxes are limited to relatively few spot measurements using expensive radiometers. While these give accurate measurement of the radiation budget for the observation station, they do not give information on regional scales for areas with strong climatological variations. Global estimates have been obtained using satellite data (e.g. Dedieu et al. 1987; Pinker and Laszlo 1992; Bishop, Rossow and Dutton 1997), but these have limited temporal coverage.

In order to derive estimates of the surface radiation budget with extensive spatial and temporal coverage, a technique for deriving surface radiation fluxes from easily obtainable meteorological data is needed. Moreover, the technique must be able to be applied over a wide range of climates, and not require extensive computer resources. Empirical formulae have been developed for estimating the surface radiation fluxes. An algorithm for reconstructing the surface solar radiation from air temperature and precipitation records has been developed for Canada (Yin 1996), with precipitation used as an index of cloudiness. The advantage of such algorithms is that measurements of temperature and precipitation are more numerous than relative humidity, sunshine hours or cloud cover. Yin found that for Canada, $95 \%$ of the variance in the global solar radiation (GSR) was found to be due to latitudinal and seasonal variation in the solar flux at the top of the atmosphere incident on a horizontal surface, with approximately $82 \%$ of the remainder statistically accounted for by the model parameterisation.

The surface solar radiation was reproduced by Bonan (1989) using linear regressions of monthly data from meteorological stations in North America, Scandinavia and the Soviet Union. For each region, a fit of the surface solar radiation as a function of the fractional cloud cover was made. Similarly, Coppolino (1992) derived single parameter fits for calculating the diffuse solar radiation at 14 locations across the globe based on the ratio of the monthly mean daily real sunshine duration to the theoretical one, finding that the site-to-site variations in the adjustable parameter were not simply dependent on latitude.

Another algorithm was developed by Nikolov and Zeller (1992), using three empirical parameters, two of which were latitude dependent (resulting in a six parameter fit to data from two stations). The algorithm uses monthly data of relative humidity and precipitation to derive the monthly mean cloud cover, based on a nonlinear regression of climate data. A third meteorological station was used to obtain a relationship for the solar flux with altitude. The resulting solar flux (incident on a horizontal surface) was converted to direct and diffuse components in order to derive the radiation incident on a tilted surface. The predicted surface flux was then compared with measured values for 69 stations in North America, Eurasia and Africa, with $5.8 \%$ error in the accumulated annual solar radiation for North America, and $10 \%$ for Eurasia and Africa.

Numerous models exist for estimating the surface solar radiation at sea. Dobson and Smith (1988) tested several commonly used models, calibrating each one at one site, and testing the result on a further 5 sites. They found that the different models gave similar RMS residuals, with daily values of $\sim 25 \mathrm{Wm}^{-2}$, and monthly values of $\sim 8 \mathrm{Wm}^{-2}$. Frouin et al. (1989) give a simple analytical formula for deriving the clear sky surface solar irradiance at sea. Input data used was aerosol type, visibility, and atmospheric column amounts of $\mathrm{H}_{2} \mathrm{O}$ and $\mathrm{O}_{3}$. Aerosol type was determined from wind data, the remaining values were determined using monthly or seasonal means. For a total of 1527 data points, the model gave a standard error of $39 \mathrm{Wm}^{-2}$ and a bias of $8 \mathrm{Wm}^{-2}$.

The algorithms presented here are based on the simple radiation transfer model of Vardavas and Koutoulaki (1995) (VK) which was derived from the radiative-convective model of Vardavas and Carver (1984). That model was used to calculate mean monthly-zonal $\left(10^{\circ}\right.$ latitude zones) values of the outgoing solar flux at the top of the atmosphere that agreed to within $5 \mathrm{Wm}^{-2}$, of the values obtained from the ERBE satellite data. The Vardavas and Carver (1984) model was recently used to derive a simple model for the longwave radiation budget by Hatzianastassiou et al. (1999), giving agreement to within $4 \mathrm{Wm}^{-2}$ of the outgoing flux values from the ERBE data. 


\section{MODIFICATIONS TO THE ALGORITHM}

The model described by VK has been extended here by adding the influence of multiple reflections between the ground and clouds (significant for situations where the surface albedo is high, i.e. snow and ice cover), as well as capturing the dependence of the atmospheric water vapour profile on temperature and cloud cover. There is also the capacity of adding the impact of aerosol scattering if the optical depth is known.

\subsection{Multiple reflections}

Cloud cover significantly reduces the solar radiation reaching the Earth's surface. However, when the surface albedo is high, there is the potential for multiple reflections between the ground and the bottom of the cloud layer, which can amplify the solar radiation. In order to make the model applicable in cold climates, it is necessary to add the impact of multiple reflections on the downwelling solar radiation.

The expression for the clear sky transmissivity given by VK, has been modified to allow for multiple reflections between the surface and the atmosphere. Assuming negligible absorption in the lower atmosphere for $\lambda<$ $850 \mathrm{~nm}$, the downwelling solar flux is enhanced through multiple reflections by a factor $\left(1+x+x^{2}+\ldots\right)$ or $1 /(1-$ $x$ ) where $x=R_{g} R_{\mathrm{d}}, R_{g}$ is the surface albedo, and $R_{d}$ is the atmospheric reflectivity for diffuse radiation. Thus the equation given by $\mathrm{VK}$ becomes

$$
t r_{s}=\frac{\left(0.6 t r_{O_{3}} t r_{r}\right)}{\left(1-R_{g} R_{d}\right)}+0.4 t r_{C O_{2}} t r_{C H_{4}} t r_{w},
$$

where $t r_{\mathrm{O}_{3}}, t r_{r}, t r_{\mathrm{CO}_{2}}, t r_{\mathrm{CH}_{4}}$ and $t r_{w}$ are the contributions to the clear sky transmissivity of $\mathrm{O}_{3}$, Rayleigh scattering, $\mathrm{CO}_{2}, \mathrm{CH}_{4}$ and $\mathrm{H}_{2} \mathrm{O}$, respectively. Assuming a typical surface albedo of 0.2 , the $R_{g} R_{d}$ term is 0.027 , resulting in a $2.8 \%$ increase in the downwelling surface flux. It should be noted that for regions covered with snow and ice, the increase in the downwelling surface flux is significant (12\% increase for a surface albedo of 0.8 ). Here, the surface albedo is assumed to be 0.8 when the air temperature is below $0^{\circ}$ and 0.2 otherwise (from measurements of the upwelling SW flux near the surface at the Surface Radiation Budget (SURFRAD) network stations and the BSRN stations at Barrow, Alaska (B), Neumayer, Antarctica (N), Ny Alesund, Norway (NA), and the South Pole (S)).

\subsection{Atmospheric water vapour}

When the atmospheric water vapour content $W_{\mathrm{H}_{2} \mathrm{O}}$ is not known, it can be estimated assuming that the variation in the water vapour mixing ratio $\eta_{\mathrm{H}_{2} \mathrm{O}}$ varies with altitude according to:

$$
\eta_{\mathrm{H}_{2} \mathrm{O}}=\eta_{\mathrm{H}_{2} \mathrm{O}, \mathrm{g}}\left(p / p_{g}\right)^{\beta}
$$

where $p$ is the pressure at the altitude in question, $\beta$ is a parameter, and the subscript $g$ refers to values at the Earth's surface (Vardavas 1987). Using this expression for the mixing ratio profile, $\mathrm{W}_{\mathrm{H} 2 \mathrm{O}}$ is given as:

$$
W_{\mathrm{H}_{2} \mathrm{O}}=0.634 r_{\mathrm{H}, \mathrm{g}} p_{s}\left(T_{g}\right) /(1+\beta) \text {, }
$$

where $r_{H, g}$ is the relative humidity and $p_{s}\left(T_{g}\right)$ is the saturated vapour pressure of water at $T_{g}$ given by:

$$
p_{s}\left(T_{g}\right)=e^{a_{1}-a_{2} / T+a_{3} \log T},
$$

where the temperature, $T$, is in Kelvin and $a_{1}, a_{2}$ and $a_{3}$ are 58.1717, 6938.67 and -5.5189 , respectively, for $T>273.15 \mathrm{~K}$ and 28.5938, 6309.64 and -0.65706, respectively, for $T \leq 273.15 \mathrm{~K}$ (Vardavas and Carver 1984).

Gaffen and Elliott (1993) found that $W_{\mathrm{H}_{2} \mathrm{O}}$ is correlated with cloud cover $\left(A_{c}\right)$ based on radiosonde data from 15 stations in the Northern Hemisphere. The increase in $W_{\mathrm{H}_{2} \mathrm{O}}$ is due to the slower decrease in the water vapour mixing ratio with height (and hence a decrease in $\beta$ ) in cloudy conditions. Assuming $r_{H, g}=0.8$ and the U.S. Standard Atmosphere temperature and pressure structure for the atmosphere with altitude, then if $\beta=3.0$, the relative humidity drops slightly in the first $4 \mathrm{~km}$, then rises to 1.0 at $\sim 10 \mathrm{~km}$. With $\beta=2.5$, the relative humidity rises to 1.0 at $\sim 5 \mathrm{~km}$. With $\beta=2.0$, the relative humidity is unity at $\sim 2.5 \mathrm{~km}$. In order to have clouds, we need $r_{H}$ near 1 at the cloud base. This implies that the value of $\beta$ in cloudy conditions is expected to be approximately 2.5 (assuming that the above expression adequately represents the distribution of water vapour with height). In clear conditions, the relative humidity does not approach 1, and so the value of $\beta$ should be greater than 3.0.

From radiosonde water vapour data for Darwin, Australia, long term (20 year) monthly mean values of $\beta$ were obtained and compared with similar data for total cloud cover (Vardavas 1987). For the range of cloud cover 
represented in the data (from 0.1 to 0.55 ), the data follow the line $\beta=3.9-2.1 A_{c}$ with a correlation coefficient $\mathrm{r}=0.81$. Using this relation, the atmospheric water vapour content for Darwin is reproduced to an accuracy of $16 \%(1 \sigma)$.

In comparison, long-term monthly averages for $10^{\circ}$ wide latitudinal zones for cloud cover (from the ISCCP C2 data covering the period from July 1983 to December 1990, (Rossow et al. 1991)), and $T_{g}, r_{H, g}$ and $W_{\mathrm{H}_{2} \mathrm{O}}$ (from the NCEP/NCAR Reanalysis Project) for data from the region for the equator to $50^{\circ} \mathrm{N}$ gave $\beta=4.0-1.9 A_{c}$ with a correlation coefficient of 0.78 , in good agreement with fit for the Darwin data. For latitudes greater than $50^{\circ}$ the slope in the $\beta$ versus $A_{c}$ relationship decreases to approximately -5.5 at $85^{\circ} \mathrm{N}$.

Values of $\beta$ obtained from radiosonde data for 8 of the stations in this study are shown in Figure 2 . These data show that for cold climates, there is a decrease in $\beta$ with decreasing temperature when $T<-10^{\circ} \mathrm{C}$. For $T<-10{ }^{\circ} \mathrm{C}, \beta$ is found to be given by $4.0 \mathrm{e}^{T / 20}-2 A_{c}$, where $T$ is in ${ }^{\circ} \mathrm{C}, \beta$ has a lower limit of -0.5 and assuming the dependence of $\beta$ on $A_{c}$ found above. For $\$ \mathrm{~T}>-10^{\circ} \mathrm{C}, \beta$ is taken to be $4-2 A_{c}$.

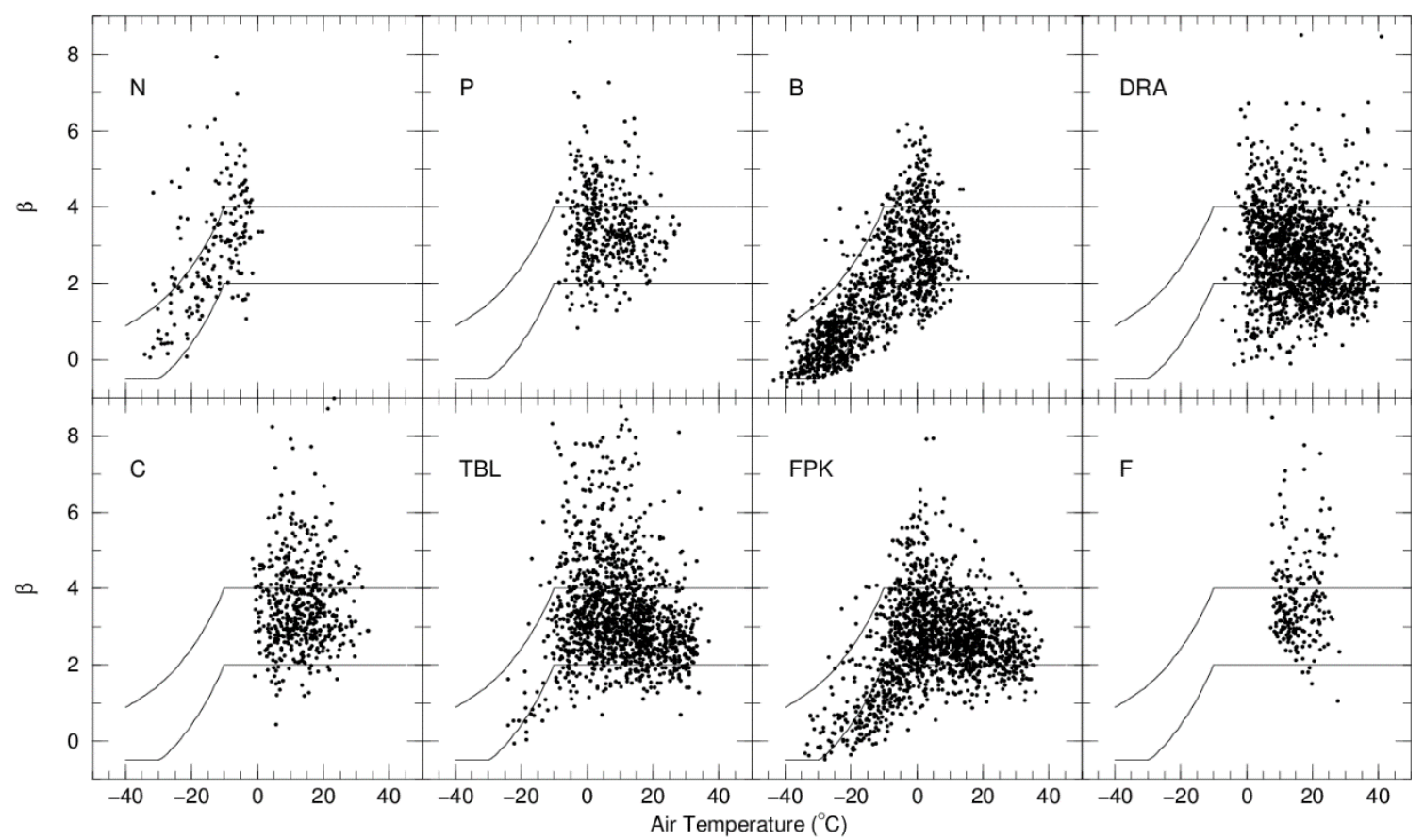

Figure 2. Variation of $b$ (derived from radiosonde data) for selected sites. Site ids (Table 1) are given in each panel. The upper line in each panel corresponds to the estimated value of $b$ for clear sky conditions, and the bottom line shows the value for $\mathrm{A}_{\mathrm{c}}=1$.

Substituting these expressions for $\beta$ enables the atmospheric water vapour content to be calculated from the cloud cover at zenith and the surface relative humidity and air temperature. It should be noted that the relationship for the parameter $\beta$ used in equation 1 was obtained using monthly average input values. While it can be applied on shorter timescales, the spatial and temporal variations in the atmospheric water vapour content, and the input parameters will result in an increased uncertainty in the derived value for $W_{\mathrm{H}_{2} \mathrm{O}}$. The effect of this uncertainty on the short-wave and long-wave downwelling fluxes is reduced given the sensitivity of the atmospheric transmissivity and effective emissivity on $W_{\mathrm{H}_{2} \mathrm{O}}$.

\section{METEOROLOGICAL DATA INPUT}

The algorithms require estimates of the cloud cover $\left(A_{c}\right)$, atmospheric water vapour content $\left(W_{\mathrm{H}_{2} \mathrm{O}}\right)$ and surface air temperature $\left(T_{g}\right)$. Equation 1 can be used to estimate $W_{\mathrm{H}_{2} \mathrm{O}}$ by including measured surface air temperature and relative humidity. Here, the daily sunshine hours are used to obtain an estimate of the cloud cover.

The meteorological data used in this study were obtained from the two automatic weather stations in Crete, one located at FORTH in Heraklion, the other near Mires in the Messara Valley. The stations measure the air temperature, relative humidity, wind (speed, direction and standard deviation), as well as the net, solar and infrared radiation fluxes. The downwelling solar radiation is measured with a pyranometer with a $180^{\circ}$ field of 
view, and sensitive from 305 to $2800 \mathrm{~nm}$. The far infrared flux is measured by a pyrgeometer. The instrument measures the far infrared ( 5 to $25 \mu \mathrm{m}$ ) radiant flux on a plane surface, and has a $150^{\circ}$ field of view. The weather station gathers data every ten seconds, and stores the mean value every fifteen minutes.

Sunshine hours for the two stations were obtained using a Campbell-Stokes sunshine recorder. For the station at FORTH (Foundation for Research and Technology, Hellas), data from Heraklion airport were used (about $10 \mathrm{~km}$ from FORTH), covering the period from March 1994 to December 1996. For the station near Mires, data covering the period from September 1994 to August 1995 for Protoria (about 25km east along the Messara Plain) were used.

\section{Cloud Cover from Sunshine Hours}

The sunshine hours can be used to estimate the daily mean cloud cover at the daily mean solar zenith angle of the sun $\bar{\alpha}$ using $A(\bar{\alpha})=1-\left(s_{h} / d_{e f f}\right)$, where $s_{h}$ is the recorded sunshine duration and $d_{e f f}$ is the effective daylength measured by the sunshine meter on a clear day, given by:

$$
d_{e f f}=\frac{1}{\pi} \cos ^{-1}\left(\frac{\cos h_{e f f}-\sin \theta \sin \delta}{\cos \theta \cos \delta}\right),
$$

where $h_{\text {eff }}$ is the effective horizon for the sunshine meter (i.e. the solar zenith angle for which the direct solar radiation is strong enough to be recorded). For Heraklion, the highest zenith angle at which the sun is detected is approximately $86^{\circ}$.

\subsection{Cloud Optical Depth}

Using data cloud fractions and scattering optical depths from Peng et al. (1982), the annual effective scattering optical depth of clouds for the northern hemisphere were found to be 8.9, with only slight variation with latitude. For the stations near the poles (B, N, NA and SP), the algorithm considerably underestimated the downwelling flux at the surface for overcast days. This implies that either the optical depth of the clouds or the absorption in the clouds is too high (or both). Leontyeva and Stamnes (1993) give daily values of cloud optical depth for cloudy days at Barrow Alaska for April to August 1988. Using these values gives an effective optical depth of 10, close to the value obtained from Peng et al. (1982). Thus for the Arctic stations, the cloud optical depth is kept at 8.9 , and the cloud absorption set to zero $(\omega=1)$. For the stations in Antarctica, the algorithm underestimates the cloudy sky flux even with $\omega=1$. As a result the cloud scattering optical depth was reduced to 6.5 for these two stations.

Table 1. Stations used.

\begin{tabular}{llllllll}
\hline Id & Station & Latitude & Longitude & Elevation & Start & End & Radiosonde \\
\hline B & Barrow, Alaska & 71.32 & -156.4 & 8 & $30 / 1 / 1992$ & $30 / 11 / 1997$ & $70026(14 \mathrm{~km})$ \\
C & Carpentras, France & 44.08 & 5.03 & 100 & $1 / 9 / 1996$ & $31 / 3 / 1999$ & $7645(55 \mathrm{~km})$ \\
FL & Florianopolis, Brazil & -27.47 & -48.48 & 11 & $2 / 7 / 1994$ & $27 / 2 / 1999$ & \\
N & Neumayer, Antarctica & -70.65 & -8.25 & 42 & $7 / 8 / 1992$ & $30 / 1 / 1998$ & 89002 \\
NA & Ny Ålesund, Norway & 78.93 & 1195 & 11 & $21 / 7 / 1993$ & $24 / 11 / 1997$ & \\
P & Payerne, Switzerland & 46.82 & 6.93 & 491 & $1 / 10 / 1992$ & $31 / 12 / 1998$ & 6610 \\
S & South Pole & -90 & - & 2841 & $15 / 1 / 1992$ & $30 / 7 / 1997$ & \\
BON & Bondville, Illinios & 40.05 & -88.37 & 213 & $16 / 4 / 1995$ & $23 / 5 / 1999$ & \\
DRA & Desert Rock, Nevada & 36.63 & -116.02 & 1007 & $17 / 3 / 1998$ & $25 / 5 / 1999$ & 72387 \\
FPK & Fort Peck, Montana & 48.31 & -105.1 & 634 & $15 / 4 / 1995$ & $25 / 5 / 1999$ & $72768(113 \mathrm{~km})$ \\
GWN & Goodwin Creek, Mississippi & 34.25 & -89.87 & 98 & $15 / 4 / 1995$ & $25 / 5 / 1999$ & \\
PSU & PSU, Pennsylvania & 40.72 & -77.93 & 376 & $29 / 6 / 1998$ & $23 / 5 / 1999$ & \\
TBL & Table Mountain, Colorado & 40.13 & -105.24 & 1689 & $20 / 6 / 1995$ & $25 / 5 / 1999$ & $72469(50 \mathrm{~km})$ \\
F & FORTH,Crete & 35.3 & 25.08 & 60 & $4 / 2 / 1994$ & $12 / 5 / 1999$ & $16754(10 \mathrm{~km})$ \\
M & Mires,Crete & 35.05 & 24.88 & 70 & $10 / 9 / 1994$ & $31 / 12 / 1998$ & \\
\hline
\end{tabular}

\section{VALIDATION WITH GROUND-BASED DATA}

Besides the two stations on Crete, data for 7 stations from the BSRN data base (Ohmura et al. 1998) and the 6 stations of the SURFRAD network (Augustine et al. 1999) were used to validate the algorithms for a large range of climates. For these stations, the daily sunshine hours were derived using measured values of the direct flux (data interval 1 to 5 minutes). This was done by calculating the number of hours for each day that the 
measured direct flux exceeded $300 \mathrm{Wm}^{-2}$ (cutoff chosen to give an effective horizon of approximately $86^{\circ}$, similar to the sunshine meter at Heraklion Airport). Details for each station are given in Table 1.

\subsection{Estimation of Atmospheric Water-Vapour Content}

Estimation of atmospheric water vapour content was validated using data from 8 stations for which daily radiosonde data were available covering a large range of climates (see Table 1). For 4 of these stations, radiosonde data from a site at a considerable distance from the radiation measuring station were used. The value of $\mathrm{W}_{\mathrm{H} 2 \mathrm{O}}$ obtained using equation (1) accounts for half of the standard deviation of the individual observed values, and $90 \%$ of the variation in the long-term mean between the different stations. It should be noted that equation 1 was applied to daily average data (due to the restriction of using sunshine hours to determine the cloud cover), while the radiosonde measurements are synoptic values. This temporal mismatch may account for some of the scatter in the residuals. Also, the increased scatter in the residuals in the last 4 panels may be due to the distance between the station and the launch point of the radiosondes. Continuous monitoring of the total atmospheric water vapour content at each station will give a better test of the algorithm derived mean daily value. Generally the long term mean water vapour content is overestimated slightly $\left(0.06 \mathrm{~g} \mathrm{~cm}^{-2}\right)$. In contrast, the summer atmospheric water vapour content for Desert Rock, Nevada is underestimated, suggesting that the algorithm overestimates the value of $\beta$ for this station.

\subsection{Downwelling IR Fluxes}

Generally the algorithm is able to reproduce the daily mean observed flux with a median absolute residual of $3.8 \mathrm{Wm}^{-2}$ and standard deviations of typically $16 \mathrm{Wm}^{-2}$. There are 4 stations with mean differences greater than $5.5 \mathrm{Wm}^{-2}$ : Neumayer, Table Mountain, FORTH and Mires. For the two stations in Crete, the mean differences are $-12 \mathrm{Wm}^{-2}$ (FORTH) and $9.6 \mathrm{Wm}^{-2}$ (Mires). These residuals could be due to instrument calibration errors of $-3.8 \%$ and $+2.8 \%$, respectively, which is within the instrument specifications. For the Neumayer station in Antarctica, the mean residual in the summer months (December to February) was $1.1 \mathrm{Wm}^{-2}$, while the residual for the entire data set (days with more than 5 daylight hours) was $8.2 \mathrm{Wm}^{-2}$. This suggests that the daily mean cloud cover derived from the measured direct solar radiation is underestimated in spring and autumn for this station. The cause of the difference between the observed and calculated flux for Table Mountain is not clear. Before September 1997, the residual was approximately $29 \mathrm{Wm}^{-2}$ with a standard deviation in the monthly residuals of $7 \mathrm{Wm}^{-2}$. From September 1997 to August 1998, the mean residual was $24 \mathrm{Wm}^{-2}$ and the standard deviation $5 \mathrm{Wm}^{-2}$, and from September 1998 to May 1999 the residual was $9 \mathrm{Wm}^{-2}$ with a standard deviation of $5 \mathrm{Wm}^{-2}$. The calibration of the instruments at the SURFRAD stations is checked each year, and the remaining 5 stations show no such variation in the residuals. The standard deviation of the residual values of monthly mean downwelling IR fluxes for each of the stations is typically between 4 and $8 \mathrm{Wm}^{-2}$.

\subsection{Downwelling SW Fluxes}

The algorithm overestimates the clear sky SW flux by $\sim 4 \mathrm{Wm}^{-2}$ (selecting days with $A_{c}<0.05$ ), and underestimates the observed flux for all conditions by $\sim 5 \mathrm{Wm}^{-2}$ (implying that the algorithm overestimates the impact of clouds by $9 \mathrm{Wm}^{-2}$ ). The RMS residual for the daily mean clear sky flux is $10 \mathrm{Wm}^{-2}$, while for all conditions, the RMS residual is $38 \mathrm{Wm}^{-2}$. A significant fraction of the RMS residual for clear sky conditions will be due to measurement and calibration errors along with uncertainty in the cloud fraction. The median RMS residual for the individual stations (clear sky) is $5.4 \mathrm{Wm}^{-2}$, with a minimum value of $3.1 \mathrm{Wm}^{-2}$.

Daily standard deviations in the residuals are typically between 20 and $30 \mathrm{Wm}^{-2}$, with biases typically less than $10 \mathrm{Wm}^{-2}$. Exceptions are the polar stations at Neumayer and the South Pole, and the station at Mires, Crete. For the Mires station, the larger bias and standard deviation of the residual could be a result of the use of sunshine hour data from a station (Protoria) $25 \mathrm{~km}$ away. This would certainly result in an increase in the scatter as clouds vary considerably over shorter distances. The larger positive bias (observed-calculated) may be indicating a higher mean cloud cover for Mires compared with Protoria, in keeping with being closer to the Psiloritis mountains. The algorithm reproduces the observed monthly mean fluxes with a typical mean residual of $-0.5 \mathrm{Wm}^{-2}$ and a typical standard deviation of $9.2 \mathrm{Wm}^{-2}$ using monthly mean input data. The difference between using monthly or daily mean input data is $1.5 \mathrm{Wm}^{-2}$ with a standard deviation of $4 \mathrm{Wm}^{-2}$.

\section{CONCLUSIONS}

We have been able to reproduce the IR and SW downwelling fluxes measured at the Earth's surface for 15 stations distributed over the globe using simple algorithms and standard meteorological data. Monthly mean derived values give RMS residuals for IR and SW fluxes of typically 6 and $9 \mathrm{Wm}^{-2}$, respectively. When applied 
on a daily timescale, the algorithms give RMS residuals of $16 \mathrm{Wm}^{-2}$ for the IR flux, and $25 \mathrm{Wm}^{-2}$ for the SW flux. The atmospheric water vapour content derived using the model gives RMS residuals of $0.3 \mathrm{~g} \mathrm{~cm}^{-2}$ in the daily mean values, and $0.13 \mathrm{~g} \mathrm{~cm}^{-2}$ in the monthly mean values.

In this case the data required are the surface temperature, water vapour content and cloud cover. Knowledge of the cloud and aerosol optical depth would improve the performance of the algorithm. The radiation values obtained from this algorithm can readily be used to estimate PE and PET using standard formulae (e.g. Penman, Priestley-Taylor, Penman-Monteith) though this may require wind speed data.

\section{REFERENCES}

Augustine, J. A., C. R. Cornwall and G. B. Hodges (1999). An integrated Surface Radiation Budget Network for Climate Research. Preprints 10th Symposium on Global Change Studies. Jan. 10-15, 1999, Dallas, TX.American Meteorological Society.

Bishop, J. K. B., W. B. Rossow, and E. G. Dutton (1997). Surface solar irradiance from the International Satellite Cloud Climatology Project 1983-1991, J. Geophys. Res. 102, 6883-6910.

Bonan, G. B. (1989). A computer model of the solar radiation, soil moisture and soil thermal regimes in Boreal Forests, Ecol. Model., 45, 275-306.

Coppolino, S. (1992). Applicability of a simple model for computing diffuse solar radiation to locations in the European, African, Asian and North American areas, Renewable Energy, 2, 469-472.

Dedieu, G., P. Y. Deschamps, and Y. H. Kerr (1987). Satellite Estimation of Solar Irradiance at the Surface of the Earth and of Surface Albedo Using a Physical Model Applied to Meteosat Data, J. Clim Appl. Meteorol., 26, $79-87$.

Dobson, F. W., and S. D. Smith (1988). Bulk models of solar radiation at sea, Q. J. R. Meteorol. Soc., 114, 165-182.

Frouin, R., D. W. Lingner, C. Gautier, K. S. Baker, and R. C. Smith (1989). A Simple Analytical Formula to Compute Clear Sky Total and Photosynthetically Available Solar Irradiance at the Ocean Surface, J. Geophys. Res. 94, 9731-9742.

Gaffen, D, J., and W. P. Elliott (1993). Column Water Vapor Content in Clear and Cloudy Skies, J. Clim., 6, 2278-2287.

Hatzianastassiou, N., B. Croke, N. Kortsalioudakis, I. Vardavas, and K. Koutoulaki (1999). A model for the longwave radiation budget of the northern hemisphere: Comparison with Earth Radiation Budget Experiment data, J. Geophys. Res. 104, 9489.

Leontyeva, E., K. Stamnes (1993). Estimations of Cloud Optical Thickness from Ground-Based Measurements of Incoming Solar Radiation in the Arctic, J. Clim., 7, 566-578.

Nikolov, N. T., and K. F. Zeller (1992). A solar radiation algorithm for ecosystem dynamic models, Ecol. Model., 61, 149-168.

Ohmura, A., E. G. Dutton, B. Forgan, C. Fröhlich, H. Gilgen, H. Hegner, A. Heimo, G. König-Langlo, B. McArthur, G. Müller, R. Philipona, R. Pinker, C. H. Whitlock, K. Dehne, and M. Wild (1998). Baseline Surface Radiation Network (BSRN/WCRP): New Precision Radiometry for Climate Research, Bull. Amer. Meteor. Soc., 79, 2115-2136.

Peng, L.I., M.-D. Chou, and A. Arking (1982). Climate studies with a multi-layer energy balance model. Part I: Model description and sensitivity to the solar constant, J. Atmos. Sci., 39, 2639-2656.

Pinker R. T., and I. Laszlo (1992). Modeling Surface Solar Irradiance for Satellite Applications on a Global Scale, J Appl Meteorol, 31, 194-211.

Rossow, W. B., L. C. Garder, P.-J. Lu, and A. Walker (1991). International Satellite Cloud Climatology Project (ISCCP). Documentation of cloud data, WMO, WCRP, 77pp.

Vardavas, I. M. (1987), Modelling the seasonal variation of net all-wave radiation flux and evaporation in a tropical wet-dry region, Ecol. Modelling, 39, 247-268.

Vardavas, I. M., and J. H. Carver (1984), Solar and terrestrial parameterizations for radiative-convective models, Planet. Space Sci., 32, 1307-1325.

Vardavas, I. M., and A. Fountoulakis (1996). Estimation of lake evaporation from standard meteorological measurements: application to four Australian lakes in different climatic regions, Ecol. Modelling, 84, 139150 .

Vardavas, I. M., and K. Koutoulaki (1995). A model for the solar radiation budget of the northern hemisphere: Comparison with Earth Radiation Budget Experiment data, J. Geophys. Res. 100, 7303-7314.

Vardavas, I.M and F.W. Taylor (2011). Radiation and Climate: Atmospheric energy budget from satellite remote sensing. Oxford University Press. ISBN 978-0-19-922717-4.

Yin, X. (1996). Reconstructing monthly global solar radiation from air temperature and precipitation records: a general algorithm for Canada, Ecol. Model., 88, 39-44. 